\title{
Brain-Derived Neurotrophic Factor Induces Mammalian Target of Rapamycin-Dependent Local Activation of Translation Machinery and Protein Synthesis in Neuronal Dendrites
}

\author{
Nobuyuki Takei, ${ }^{1}$ Naoko Inamura, ${ }^{1}$ Mihoko Kawamura, ${ }^{1}$ Hisaaki Namba, ${ }^{1}$ Kenta Hara, ${ }^{2,3}$ Kazuyoshi Yonezawa, ${ }^{2,3}$ and \\ Hiroyuki Nawa ${ }^{1}$ \\ ${ }^{1}$ Department of Molecular Neurobiology, Brain Research Institute, Niigata University, Niigata 951-8585, Japan, ${ }^{2}$ Biosignal Research Center, Kobe \\ University, Kobe 657-8501, Japan, and ${ }^{3}$ Core Research for Evolutional Science and Technology, Japan Science and Technology Corporation, Saitama 332- \\ 0012, Japan
}

In neurons, perisynaptic or dendritic translation is implicated in synapse-wide alterations of function and morphology triggered by neural activity. The molecular mechanisms controlling local translation activation, however, have yet to be elucidated. Here, we show that local protein synthesis and translational activation in neuronal dendrites are upregulated by brain-derived neurotrophic factor (BDNF) in a rapamycin and small interfering RNA specific for mammalian target of rapamycin (mTOR)-sensitive manner. In parallel, BDNF induced the phosphorylation of tuberin and the activation of mTOR in dendrites and the synaptoneurosome fraction. mTOR activation stimulated translation initiation processes involving both eIF4E/4E-binding protein (4EBP) and p70S6 kinase/ribosomal S6 protein. BDNF induced phosphorylation of 4EBP in isolated dendrites. Moreover, local puff application of BDNF to dendrites triggered S6 phosphorylation in a restricted area. Taken together, these data indicate that mTOR-dependent translation activation is essential for the upregulation of local protein synthesis in neuronal dendrites.

Key words: BDNF; local protein synthesis; mTOR; neuron; raptor; translation; tuberin

\section{Introduction}

Novel protein synthesis plays key roles in the formation of synapses and the modulation of long-term synaptic plasticity, which are associated with learning and memory in the brain (Bailey et al., 1996). In particular, activity-dependent, local protein synthesis in neuronal dendrites and perisynaptic sites is thought to underlie synapse-wide alterations of function and morphology (Martin et al., 2000; Jiang and Schuman, 2002). Recent studies have shown that dendrites possess all the components necessary for translation, containing ribosomes (Steward and Levy, 1982), mRNAs (Job and Eberwine, 2001), and translation factors (Gardiol et al., 1999; Inamura et al., 2003), and protein synthesis has been observed to occur in dendrites (Steward and Schuman, 2001). Thus, it has been hypothesized that neural activity enhances local protein synthesis in dendrites, which in turn induces

Received 0ct. 2, 2003; revised Sept. 14, 2004; accepted Sept. 14, 2004.

This work was supported by research grants from the Ministry of Health, Labor, and Welfare; the Ministry of Education, Culture, Sports, Science, and Technology (grant-in-aid for Priority Area); the Japanese Society for the Promotion of Science [grant-in-aid for Scientific Research (B) and grant-in-aid for Creative Scientific Research]; and the Novartis Foundation. We thank Kyoko Ishii and Eiko Higuchi for technical assistance and Sumitomo Pharmaceuticals for kindly supplying recombinant BDNF.

Correspondence should be addressed to Dr. Nobuyuki Takei, Department of Molecular Neurobiology, Brain Research Institute, Niigata University, Asahimachi 1, Niigata 951-8585, Japan. E-mail: nobtak@bri.niigata-u.ac.jp. DOI:10.1523/JNEUROSCI.1427-04.2004

Copyright $\odot 2004$ Society for Neuroscience $\quad$ 0270-6474/04/249760-10\$15.00/0 or maintains synaptic plasticity. Among several stimulants of local protein synthesis, brain-derived neurotrophic factor (BDNF) increases the synthesis of plasticity-related molecules, such as Arc and calcium/calmodulin-dependent kinase II $\alpha$ (CaMKII $\alpha)$, in dendrites (Aakalu et al., 2001; Yin et al., 2002). BDNF regulates neural activity and controls synaptic plasticity in the brain (Thoenen, 1995; Poo, 2001), and we have reported that BDNF increases global protein synthesis by activating translation cascades in neurons (Takei et al., 2001). Thus, BDNF may be a key modulator that links local protein synthesis to synaptic plasticity. The molecular mechanisms underlying local protein synthesis, however, have yet to be elucidated. In postmitotic neurons, rapamycin acts as a suppressor of plastic changes in neural function (Casadio et al., 1999; Tang et al., 2002), suggesting a role for mammalian target of rapamycin (mTOR) in neural plasticity. $\mathrm{mTOR}$ is the target of rapamycin and is a protein kinase of the phosphatidylinositol kinase-related kinase family. It functions as a critical regulator of cell growth by controlling translation in response to nutrients and growth factors (Gingras et al., 2001). Recent findings show that tuberin and hamartin regulate mTOR activity (Gao et al., 2002; Inoki et al., 2002). mTOR, with its binding partner, raptor (Hara et al., 2002, Kim et al., 2002), phosphorylates eukaryotic initiation factor $4 \mathrm{E}$ (eIF4E)-binding protein 1 (4EBP1) (Isotani et al., 1999). In eukaryotic cells, the rate of translation is primarily regulated at the initiation phase 
(Mathews et al., 2000), and 4EBP1 behaves as a negative regulator of initiation, binding to eIF4E, a cap-binding factor, and preventing the formation of the eIF4F complex in translationally silent states. Phosphorylation of $4 \mathrm{EBP} 1$ causes it to dissociate from eIF4E and permits the activation of initiation. Consequently, activation of mTOR enhances cap-dependent translation. mTOR also phosphorylates p70S6 kinase (p70S6K) and induces phosphorylation of its substrate, ribosomal S6 protein (S6) (Fumagalli and Thomas, 2000). This process enhances translation initiation of $5^{\prime}$-oligopyrimidine tract-containing mRNAs, such as ribosomal proteins and elongation factors. Thus, mTOR is involved in multiple cascades of translational control. Here, we report the molecular basis for mTOR-dependent local activation of the translation machinery, and this activation leads to local protein synthesis in the dendrites of cortical neurons after exposure to BDNF.

\section{Materials and Methods}

Materials. BDNF was a generous gift from Sumitomo Pharmaceuticals (Osaka, Japan). An anti-4EBP1 polyclonal antibody was purchased from Santa Cruz Biotechnology (Santa Cruz, CA), and an anti-eIF4E polyclonal antibody was obtained from Transduction Laboratories (Lexington, KY). Anti-phospho-mTOR (Ser2448), anti-tuberin, antiphosopho-tuberin (Thr1462), anti-phospho-4EBP1 (Thr37 or Thr37/ 46), anti-phospho-p70S6K (Thr389), and anti-phospho-S6 (Ser240/ 244) polyclonal antibodies were from Cell Signaling. Antibodies against these molecules used as loading controls were purchased from the same company. An anti-mTOR monoclonal antibody (Nishiuma et al., 1998), anti-raptor polyclonal antibody (Hara et al., 2002), and glutathione $S$-transferase (GST)-fused 4EBP1 (GST-4EBP1) (Nishiuma et al., 1998) were prepared as described previously. $\left[{ }^{35} \mathrm{~S}\right]$ Methionine, $\left[\gamma_{-}{ }^{32} \mathrm{P}\right] \mathrm{ATP}$, and protein G-Sepharose were purchased from Amersham Biosciences. Rapamycin was obtained from Calbiochem (La Jolla, CA).

Preparation of primary culture and isolated dendrites. A primary culture of cortical neurons was prepared as described previously (Takei et al., 1998). Briefly, cortical neurons were used for each assay after culture for 10-14 d in DMEM (Nissui, Tokyo, Japan) containing 10\% fetal bovine serum (Invitrogen, San Diego, CA). For measuring the rate of protein synthesis, metabolic labeling with $\left[{ }^{35} \mathrm{~S}\right]$ methionine was performed as reported previously (Takei et al., 2001). Isolated dendrites were prepared according to the method reported by Torre and Steward (1992), with slight modifications. Neurons were seeded onto Nuclepore membranes with a $3 \mu \mathrm{m}$ diameter pore and attached to glass coverslips that were coated with poly-L-lysine and laminin and overlaid with $1 \%$ methylcellulose-containing medium. The edges were covered with silicon rubber to maintain attachment to the membrane and glass. After $5 \mathrm{~d}$ in culture, cells were serum starved, and the membrane was removed. Samples were allowed to rest $1 \mathrm{hr}$ before stimulation. The neurites remaining on the coverslip were stimulated with BDNF or BDNF plus rapamycin for 5 and $30 \mathrm{~min}$ for immunostaining or metabolic labeling, respectively. Isolated dendrites could respond to BDNF at least $3 \mathrm{hr}$ after isolation. Only preparations containing no cell bodies, as assessed by nuclear staining using propiodium iodide, were used for experiments.

Preparation of synaptoneurosomes. Synaptoneurosomes were prepared as reported previously (Scheetz et al., 2000), with modifications. Briefly, postnatal day 14-18 rats were anesthetized with carbon dioxide and decapitated, according to the National Institutes of Health and our institutional guidelines for the care and use of laboratory animals, and cerebral cortices were removed. Tissues were homogenized in ice-cold $\mathrm{Ca}^{2+}$, $\mathrm{Mg}^{2+}$-free HBSS supplemented with RNase inhibitor, AP-5, CNQX, and anti-BDNF antibody. Samples were passed through nylon filters of decreasing pore size $(150,60,30$, and $10 \mu \mathrm{m})$. Supernatants obtained after centrifugation for $1 \mathrm{~min}$ at $4000 \times g$ were again centrifuged for $4 \mathrm{~min}$ at $14,000 \times g$. All procedures were performed at $4^{\circ} \mathrm{C}$. Although the collected fraction could contain nonsynaptic components, PSD-95 (postsynaptic density protein-95) and glutamate receptor 1 were enriched, and only a trace amount of glial marker (GFAP) was detected (data not shown). Pellets were resuspended with DMEM and treated with BDNF and/or rapamycin for the indicated time. For metabolic labeling, $\left[{ }^{35} \mathrm{~S}\right]$ methionine $(50 \mu \mathrm{Ci} / 50 \mu \mathrm{g}$ protein $/ 500 \mu \mathrm{l})$ was incubated for $30 \mathrm{~min}$ at $37^{\circ} \mathrm{C}$.

Puffapplication of BDNF. BDNF ( $200 \mathrm{ng} / \mathrm{ml})$ was applied by puffing 30 times for a $200 \mathrm{msec}$ duration and $5 \mathrm{sec}$ interval, using a pneumatic picopump. To avoid the diffusion of applied BDNF to other sites (i.e., cell body), BDNF was applied perpendicular to the dendrite, and dye flow was monitored to insure local dendrite application. Three minutes after puffing was complete, neurons were fixed and processed for immunocytochemistry.

Cell autoradiography. Cultured neurons were starved of serum as described for metabolic labeling and incubated with a tritium-labeled amino acid mixture $(1.5 \mu \mathrm{Ci} / \mathrm{ml})$ for $15 \mathrm{~min}$ with or without BDNF, in the presence or absence of rapamycin. After washing with ice-cold PBS three times, tritium-incorporated proteins were fixed with $3 \%$ acetic acid in PBS. Free amino acids were washed away with PBS, and neurons were incubated with $\mathrm{RNaseH}(20 \mathrm{mg} / \mathrm{ml})$ overnight at room temperature. After washing and drying, culture plates were dipped into emulsion (Eastman Kodak, Rochester, NY), developed, and analyzed by autoradiography. Protein synthesis was quantitated by counting the number of grains in each neuron in a blinded manner. Although each grain may not indicate a single protein (it may contain several molecules), the number of grains approximately reflects the amount of newly synthesized proteins.

Immunocytochemistry. Neurons in culture were fixed with $4 \%$ paraformaldehyde in $0.1 \mathrm{~m}$ phosphate buffer, $\mathrm{pH} 7.4$, and washed with PBS. Neurons were incubated overnight at $4^{\circ} \mathrm{C}$ with PBS containing $5 \%$ skim milk and $0.3 \%$ Triton X-100 to absorb nonspecific binding. Neurons were incubated with the indicated primary antibodies for 3-8 hr. Alexa Fluor 488 (green)-conjugated anti-mouse IgG or Alexa Fluor 546 (red)conjugated anti-rabbit IgG antibodies (Molecular Probes, Eugene, OR) were used as a secondary antibody. Immunoreactivity was observed under an Axioskop fluorescent microscope (Zeiss, Oberkochen, Germany), and photomicrographs were captured using a digital camera $(1392 \times$ 1040 pixels; Olympus, Tokyo, Japan). For all immunocytochemistry, signals were not detected in the absence of primary antibodies.

Image analysis. Captured neuron images were analyzed using imaging software (LuminaVison; Olympus). The dendritic area was calculated by extracting and measuring MAP2-positive dendrites (green fluorescence for double immunocytochemistry, and blue for triple immunocytochemistry), and the intensity of red fluorescence, which reflected the signals of phosphorylated molecules such as P-mTOR, P-4EBP, and $\mathrm{P}-\mathrm{p} 70 \mathrm{~S} 6 \mathrm{~K}$, in each dendrite was also measured. Analysis was performed on 100 neurons chosen randomly from three to four different culture dishes in each group in a blinded manner.

Immunoprecipitation, in vitro phosphorylation, in vitro kinase assay, and Western blotting. For the metabolic labeling and immunoprecipitation of Arc and CaMKII, synaptoneurosomes were incubated with $\left[{ }^{35} \mathrm{~S}\right]$ methionine, with or without BDNF and rapamycin, for $30 \mathrm{~min}$ at $37^{\circ} \mathrm{C}$. Samples were then lysed in equal volumes of $2 \times$ radioimmunoprecipitation assay (RIPA) buffer (100 mM Tris $\mathrm{HCl}, 0.2 \%$ SDS, $2 \%$ Triton-X100, and $2 \%$ sodium deoxycholate, $\mathrm{pH}$ 7.4) containing Complete protease inhibitor mixture (Roche), $2 \mathrm{~mm} \mathrm{Na}_{3} \mathrm{VO}_{4}$, and $40 \mathrm{~mm} \mathrm{NaF}$. The supernatants from the centrifuged samples were preincubated with protein G-Sepharose for $30 \mathrm{~min}$, to adsorb nonspecific binding, and were then incubated overnight with primary antibodies. Protein G-Sepharose was incubated with the samples for an additional $3 \mathrm{hr}$. Immunocomplexes were then washed five times in RIPA buffer. SDS sample buffer was added to each sample and heated to $95^{\circ} \mathrm{C}$ for $5 \mathrm{~min}$. Each sample was subjected to SDS-PAGE, and autoradiography was performed after drying the gel. Tuberin phosphorylation in the synaptoneurosome fraction was examined as described above, with some modifications. Synaptoneurosomes were incubated with $\left[\gamma_{-}{ }^{32} \mathrm{P}\right]$ ATP for $30 \mathrm{~min}$. Samples were then stimulated with BDNF for $5 \mathrm{~min}$. In experiments using the inhibitor Ly29002, samples were preincubated with the compound for $10 \mathrm{~min}$ Samples were then immunoprecipitated with anti-tuberin and applied for SDS-PAGE, followed by autoradiography. mTOR immunoprecipitation and kinase assays were performed essentially as described previously (Nishiuma et al., 1998; Takei et al., 2001). For the analysis of mTOR/ raptor binding, samples were immunoprecipitated with anti-mTOR an- 
tibody, and Western blotting was performed with anti-raptor antibody. Synaptoneurosomes were incubated with $2 \times$ mTOR buffer (in mM: 50 Tris/HCl, pH 8.0, $150 \mathrm{NaCl}, 40 \mathrm{NaF}, 2 \mathrm{Na} 3 \mathrm{VO} 4,2$ EDTA, 10 EGTA, 40 $\beta$-glycerophosphate, 2 dithiothreitol, and Complete). In coimmunoprecipitation (Co-IP) experiments, synaptoneurosomes were lysed by $2 \times$ Co-IP buffer (20 mu Tris $\mathrm{HCl}, 300 \mathrm{~mm} \mathrm{NaCl}, 2 \%$ Triton X-100, and $1 \%$ Nonidet P-40) containing Complete, $2 \mathrm{~mm} \mathrm{Na}_{3} \mathrm{VO}_{4}$, and $40 \mathrm{~mm} \mathrm{NaF}$ and immunoprecipitated with an anti-4EBP1 antibody. Samples were subjected to SDS-PAGE, and Western blotting was performed with antieIF4E antibody to detect 4EBP-associated eIF4E. SDS-PAGE and Western blotting were performed as described previously (Takei et al., 2001). For all Co-IP experiments, protein $\mathrm{G}$ without antibodies did not pull down target molecules.

Small interfering RNA-mediated knock-down of mTOR. To reduce the level of mTOR protein, double-stranded $21 \mathrm{bp} \mathrm{RNA}$ with TT overhangs complementary to a rat mTOR mRNA (215-235 region) was synthesized and conjugated with FITC (Greiner Japan). The sequence used was as follows: sense, 5' -CUUCGAGAGAUGAGUCAGGTT-3'; antisense, 3' TTGAAGCUCUCUACUCAGUCC- $5^{\prime}$. The sequence corresponded to human mTOR mRNA 231-251 (Kristof et al. 2003). As a negative control, a rhodamine-labeled 21 bp double-stranded RNA that was not complementary to any mRNA (Qiagen, Hilden, Germany) was used. Transfection of small interfering RNA (siRNA) was performed with RNAiFect reagent (Qiagen) according to the manufacturer's protocol. To avoid a nonspecific toxic effect, medium was changed after $24 \mathrm{hr}$ of siRNA addition. After serum starvation, BDNF was applied for $5 \mathrm{~min}$. Samples for Western blotting and fixation for immunocytochemistry were performed $48 \mathrm{hr}$ after siRNA transfection.

\section{Results}

\section{Rapamycin-sensitive local protein synthesis}

The effects of BDNF on local protein synthesis in neuronal dendrites were examined in situ. Neurons were incubated with tritium-labeled amino acids for $15 \mathrm{~min}$ with or without BDNF $(100 \mathrm{ng} / \mathrm{ml})$, in the presence or absence of rapamycin $(20 \mathrm{ng} / \mathrm{ml})$. The doses of BDNF and rapamycin were determined according to the previous study (Takei et al., 2001). After treatment, neurons were fixed, dipped into emulsion, and analyzed by autoradiography (Fig. 1). Newly synthesized proteins that incorporated tritium were visualized as individual grains. Treatment of cells with BDNF led to increased protein synthesis in both the cell body and dendrites, and these effects were blocked by pretreatment with rapamycin (Fig. 1D). When protein synthesis was completely blocked with anisomycin, substantially fewer grains were visible ( $21 \pm 6$ in the cell body and $36 \pm 11$ in neurites). To further confirm the ability of BDNF to induce local protein synthesis in neurites, $\left[{ }^{35} \mathrm{~S}\right]$ methionine incorporation was measured in two different preparations. BDNF increased protein synthesis in the synaptoneurosomes, a concentrated fraction of presynaptic and postsynaptic components prepared from rat brain. Additionally, $\left[{ }^{35} \mathrm{~S}\right]$ methionine incorporation was increased in isolated dendrites and axons, obtained from cultured neurons, as well as in cultured neurons after treatment with BDNF. Again, the increased rate of protein synthesis induced by BDNF was blocked by rapamycin (Table 1). These results strongly suggest that BDNF-induced local protein synthesis is mTOR dependent.

To assess a possible link between BDNF-induced local protein synthesis and synaptic plasticity, attempts were made to identify the molecules that are related to synaptic functions. Arc and CaMKII $\alpha$ mRNAs are distributed in dendrites, and their translation is enhanced by BDNF, so that translation and rapamycin sensitivity of these two molecules were quantitatively examined in synaptoneurosomes, by metabolic labeling with $\left[{ }^{35} \mathrm{~S}\right]$ methionine, followed by immunoprecipitation. As seen in Figure 1, levels of newly synthesized Arc (Fig. $1 E$ ) and CaMKII $\alpha$ (Fig. $1 F$ )
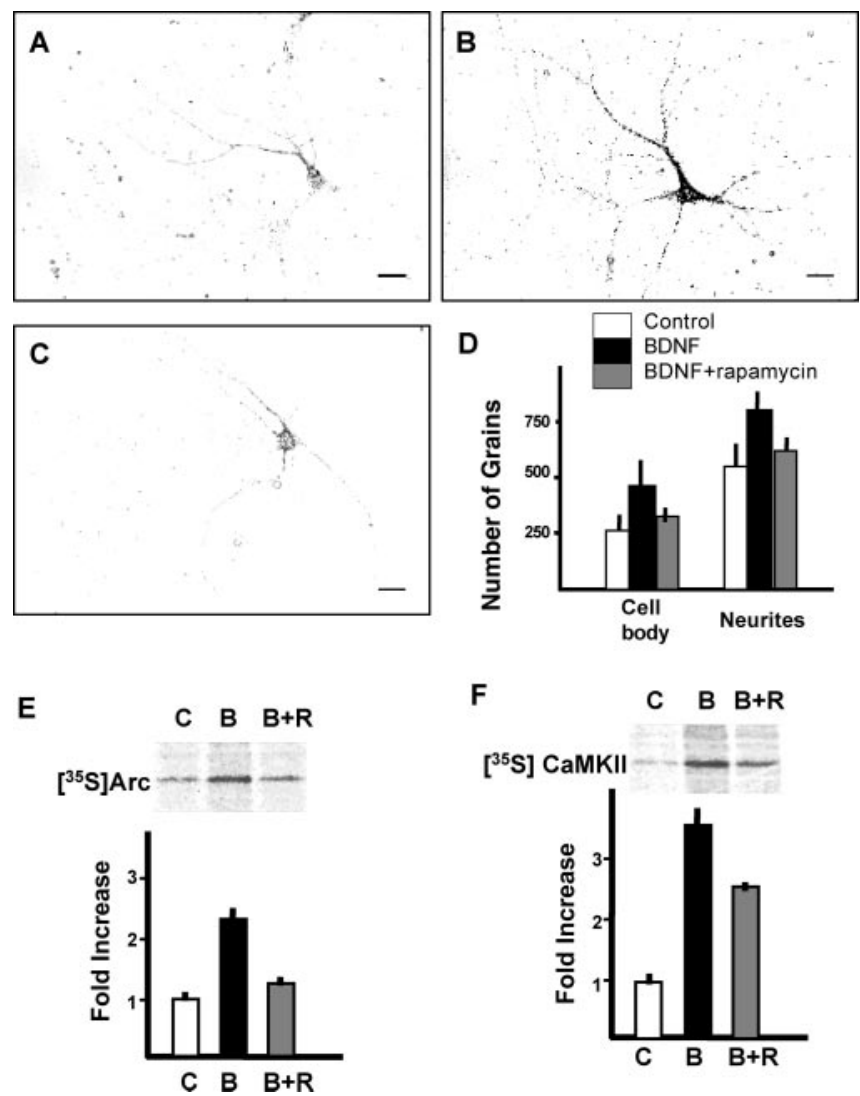

Figure 1. Rapamycin-sensitive novel protein synthesis induced by BDNF in neurites. Photomicrographs of cells after tritium incorporation are shown for control $(A), \operatorname{BDNF}(100 \mathrm{ng} / \mathrm{ml}$; $B)$, and BDNF plus rapamycin ( $20 \mathrm{ng} / \mathrm{ml} ; O)$. Scale bars, $20 \mu \mathrm{m}$. D, Quantitation of grains on cell bodies and dendrites. Bars (white, control; black, BDNF; gray, BDNF plus rapamycin) represent means $\pm S D$ ( $n=68$ of randomly chosen cells from 3-4 different culture dishes). $E, F$, Autoradiography and densitometric analysis of immunoprecipitated $\operatorname{Arc}(E)$ and CaMKII $(F)$ after labeling synaptoneurosomes with $\left[{ }^{35} \mathrm{~S}\right]$ methionine for $30 \mathrm{~min}$. Bars (white, control; black, BDNF; gray, BDNF plus rapamycin) represent means \pm SD $(n=3)$.

\section{Table 1. BDNF increased novel protein synthesis in different preparations}

\begin{tabular}{llll}
\hline & \multicolumn{2}{l}{ Percentage of control } \\
\cline { 2 - 4 } & Control & BDNF & $\begin{array}{c}\text { BDNF plus } \\
\text { rapamycin }\end{array}$ \\
\hline Cultures $(n=6)$ & $100 \pm 6$ & $168 \pm 5^{*}$ & $106 \pm 5$ \\
Synaptoneurosomes $(n=4)$ & $100 \pm 9$ & $196 \pm 11^{*}$ & $101 \pm 12$ \\
Isolated dendrites $(n=3)$ & $100 \pm 7$ & $174 \pm 6^{*}$ & $98 \pm 6$ \\
\hline
\end{tabular}

${ }^{*} p<0.005$ ( $t$ test).

increased $\sim 2.3$ - and 3.3-fold, respectively, during the $30 \mathrm{~min}$ labeling period. Interestingly, whereas BDNF-induced Arc synthesis was completely blocked by rapamycin, CaMKII $\alpha$ synthesis was only partially inhibited.

\section{mTOR distribution and activation in dendrites}

Because pharmacological experiments suggested that mTOR signaling is involved in BDNF-induced local protein synthesis, the distribution of mTOR and raptor, a binding partner and regulator of mTOR, was examined in dendrites. Examination of cortical neurons by double immunocytochemistry with anti-MAP2 and anti-mTOR (data not shown) or anti-MAP2 and anti-raptor (Fig. $2 A-C$ ) indicated that these molecules colocalized to both the cell body and dendrites. Colocalization of $\mathrm{mTOR}$ and raptor was also observed in dendrites (Fig. 2D-F). In addition, an interaction 

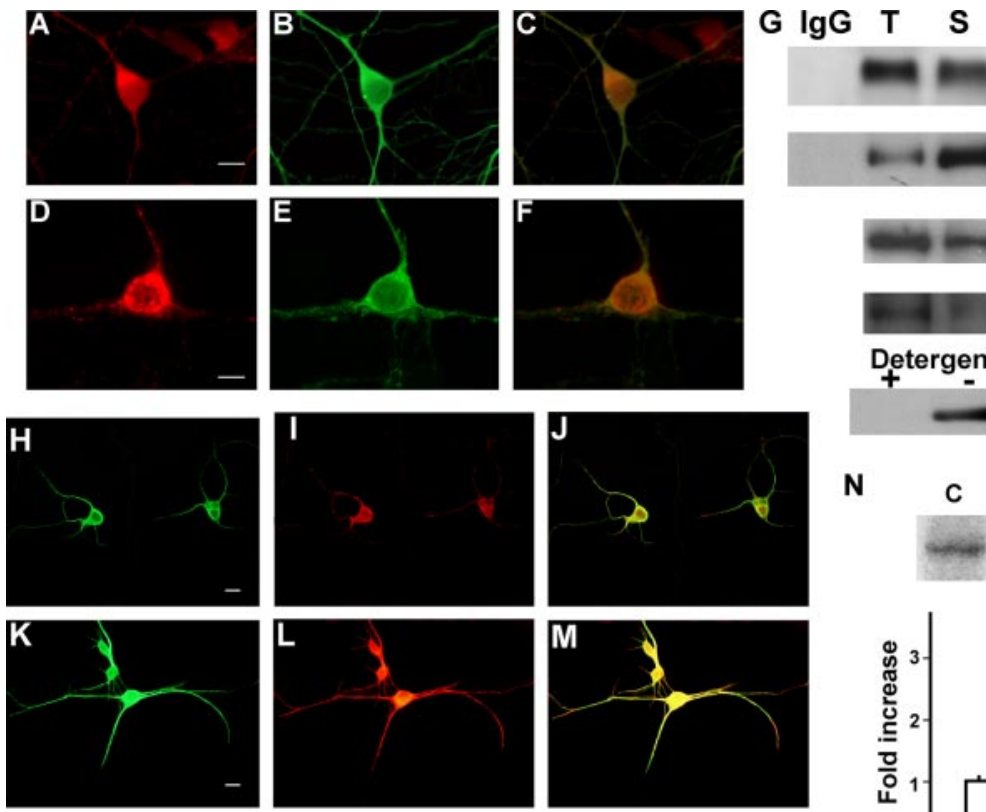

o

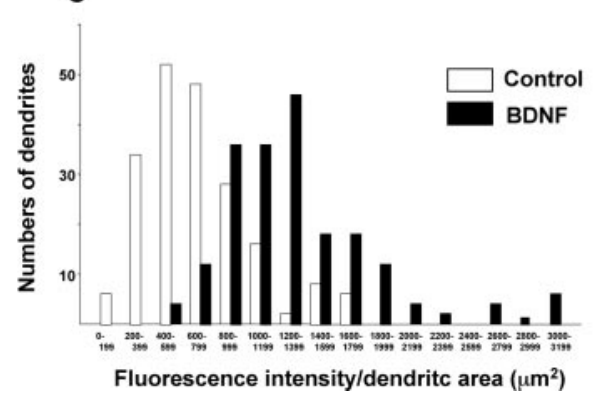

Figure 2. Distribution of mTOR and raptor and activation of mTOR by BDNF in dendrites. Double immunocytochemistry of raptor $(A)$ and MAP2 $(B)$ are shown. The merged image is shown in C. Double immunocytochemistry of $\mathrm{mTOR}(D), \operatorname{raptor}(E)$, and their merged image $(F)$ are shown. Scale bars, $10 \mu \mathrm{m}$. $G$, Western blotting of mTOR-associated raptor and mTOR itself were detected in total lysate (T) and in synaptoneurosomes (S), after immunoprecipitation with anti-mTOR antibody. IgG indicates normal mouse lgG that was used as a control for immunoprecipitation. Western blotting of raptor in total lysate or synaptoneurosome lysate is also presented. Detergent sensitivity of the association is shown in the bottom panel. Phosphorylation of mTOR in control $(H-J)$ and BDNF (100 ng/ml)-treated $(K-M)$ neurons was detected by immunocytochemistry with anti-phospho-mTOR (I, L). Double immunostaining was performed with anti-MAP2 antibody $(H, K)$. Merged images are shown in $J$ and $M$. Scale bars, 10 $\mu \mathrm{m}$. Enhancement of mTOR kinase activity against recombinant GST-4EBP1 in synaptoneurosomes is shown. C, Control; B, BDNF $(100 \mathrm{ng} / \mathrm{ml}) ; \mathrm{B}+\mathrm{R}, \mathrm{BDNF}$ plus rapamycin $(20 \mathrm{ng} / \mathrm{ml})$. Phosphorylated GST-4EBP1 was detected by autoradiography after SDSPAGE and analyzed by densitometry $(n=4) .{ }^{*} p<0.005$ (ANOVA). Summary histogram indicating the fluorescence intensity distributions for control and BDNF-treated dendrites ( $n=100$ of randomly chosen cells from 3-4 different culture dishes in each group). Dendritic area was calculated by measuring MAP2-positive dendrites (green fluorescence), and the intensity of red fluorescence, which reflected phospho-mTOR signal, in each dendrite was measured (0). A summary diagram indicating the mean intensity in dendrites of both conditions is shown in $P$. Bars represent mean + SD. ${ }^{*} p<0.001$ ( $t$ test). to phosphorylate 4EBP1 was examined in the synaptoneurosome fraction. mTOR immunoprecipitates from BDNF-treated synaptoneurosomes strongly phosphorylated GST-fused recombinant 4EBP1 in vitro (Fig. $2 \mathrm{~N}$ ). These results argue that BDNF induces mTOR phosphorylation and kinase activity in dendrites. To further quantify mTOR phosphorylation in dendrites, fluorescence intensity in dendrites was calculated after staining with antiphospho-mTOR. As seen in Figure 2O, BDNF treatment increased the number of dendrites that showed stronger signal of phospho-mTOR. The average fluorescence intensity was also significantly increased by BDNF treatment (Fig. 2P).

\section{Distribution of tuberin and RheB and activation of tuberin by BDNF in dendrites}

To better understand the upstream signals that link BDNF/TrkB and mTOR, we examined the activation of tuberin, a modulator of mTOR signaling, in dendrites. Double immunocytochemistry with antiMAP2 showed that tuberin and its downstream small G-protein RheB were present in both the dendrites and cell bodies of cortical neurons (Fig. $3 A-F$ ). When neurons were treated with BDNF for $5 \mathrm{~min}$, the phospho-tuberin (Thr1462) signal was increased in both cell bodies and dendrites (Fig. 3G-L). Additionally, after treatment with BDNF, tuberin became phosphorylated in synaptoneurosomes (Fig. 3M, top). This finding was confirmed by blotting synaptoneurosomes treated with or without BDNF (or BDNF plus Ly294002) with anti-phospho-tuberin (Thr1462) (Fig. $3 M$, middle) or anti-tuberin (Fig. $3 M$, bottom). The phosphorylation of tuberin induced by BDNF was completely inhibited by Ly294002, a phosphatidylinositol-3 kinase (PI3K) inhibitor. These results suggest that tuberin is phosphorylated after BDNF treatment and thereby releases the suppression of mTOR through RheB in dendrites. between mTOR and raptor was confirmed in the synaptoneurosomal fraction, as revealed by Co-IP of raptor with mTOR. Interestingly, mTOR-bound raptor was enriched in the synaptoneurosomal fraction compared with denucleated total lysate (Fig. $2 G)$. This association was disrupted by incubating with detergent, as reported previously (Hara et al., 2002).

To examine whether BDNF activated mTOR in dendrites, the phosphorylation state of mTOR after BDNF treatment was examined by immunocytochemistry using anti-phospho-mTOR (Ser2448) and anti-MAP2 antibodies. Phosphorylation of mTOR, which reflects its activation, was observed after stimulation with BDNF for 5 min within both the cell bodies and dendrites of cortical neurons (Fig. $2 H-M$ ). To determine whether mTOR localized to dendrites was functional, the ability of mTOR

\section{Translational activation in synaptoneurosomes}

We have shown that tuberin is phosphorylated downstream of BDNF treatment in a PI3K-dependent manner. Figure $4 A$ incorporates this finding into our current understanding of the mTOR signaling pathway. After phosphorylation of tuberin, mTOR becomes activated and phosphorylates 4EBP and p70S6K. Phosphorylated 4EBP dissociates from eIF4E and permits the formation of the eIF4F complex. When p70S6K is phosphorylated, it phosphorylates ribosomal S6 protein. Both of these events contribute to translational activation.

To further understand the initiation of translation in dendrites, we looked for activation of molecules downstream of $\mathrm{mTOR}$ in synaptoneurosomes. To further explore the regulation of translation in dendrites, biochemical analysis was performed 
using the synaptoneurosomal fraction. Phosphorylation of Thr37/46 of 4EBP1 was increased by BDNF as revealed by anti-phospho-specific antibody. Treatment of synaptoneurosomes with BDNF reduced the association between 4EBP1 and eIF4E in a rapamycin-sensitive manner (Fig. 4B). Phosphorylation of p70S6K, another substrate of mTOR, and S6, a substrate of p70S6K, was also increased by BDNF treatment in a rapamycin-sensitive manner (Fig. 4B). Western blotting with antibodies that recognize the phospho and non-phospho forms of these molecules showed no changes in the overall amount of each molecule (Fig. 4B).

Translational activation in dendrites Immunocytochemistry was performed using anti-phospho-4EBP1 (Thr37), antiphospho-p70S6K (Thr389), and antiphospho-S6 (Ser240/244). Phosphorylated 4EBP1 increased in multiple dendrites of BDNF-treated neurons compared with control-treated neurons (Fig. $5 A, B$ ), as revealed by costaining with anti-MAP2 antibody (Fig. 5D,E). Rapamycin inhibited the observed increase in phosphorylated 4EBP1 (Fig. 5C,F). BDNF also increased the phosphorylation of p70S6K (Fig. 5G-I) and its substrate S6 (Fig. 5M-O) in MAP2immunopositive dendrites (Fig. 5, $J-L$ and $P-R$, respectively). In all immunocytochemical experiments, neurons were fixed after 5 min of BDNF stimulation. The data from multiple experiments are summarized in Figure $6, A$ and $C$. BDNF treatment increased the number of dendrites that showed stronger signal of phospho-4EBP (Fig. 6A) and phospho-S6K (Fig. 6C). The fluorescent signal per dendrite area for phospho-4EBP and $-\mathrm{p} 70 \mathrm{~S} 6 \mathrm{~K}$ increased significantly after BDNF treatment, and these increases were completely blocked by rapamycin. The average intensity of all dendrites was significantly increased by BDNF, and these changes were also inhibited by rapamycin (Fig. $6 B, D$ ). Thus, BDNF stimulates at least two translation initiation pathways downstream of mTOR in dendrites.

\section{Effect of mTOR siRNA on}

BDNF-induced translational activation and protein synthesis

To further confirm the direct involvement of mTOR in BDNF-induced translational activation and protein synthesis, siRNA was used to knockdown mTOR protein levels. As shown in Figure 7A, siRNA successfully reduced mTOR protein levels in cultured cortical neurons. In mTOR siRNA-transfected neurons, phosphorylated mTOR and phosphorylated p70S6K were also reduced, whereas glyceraldehyde-3-phosphate dehydrogenase, a control, was unchanged (Fig. $7 A, C$ ). These results strongly suggest that reductions in
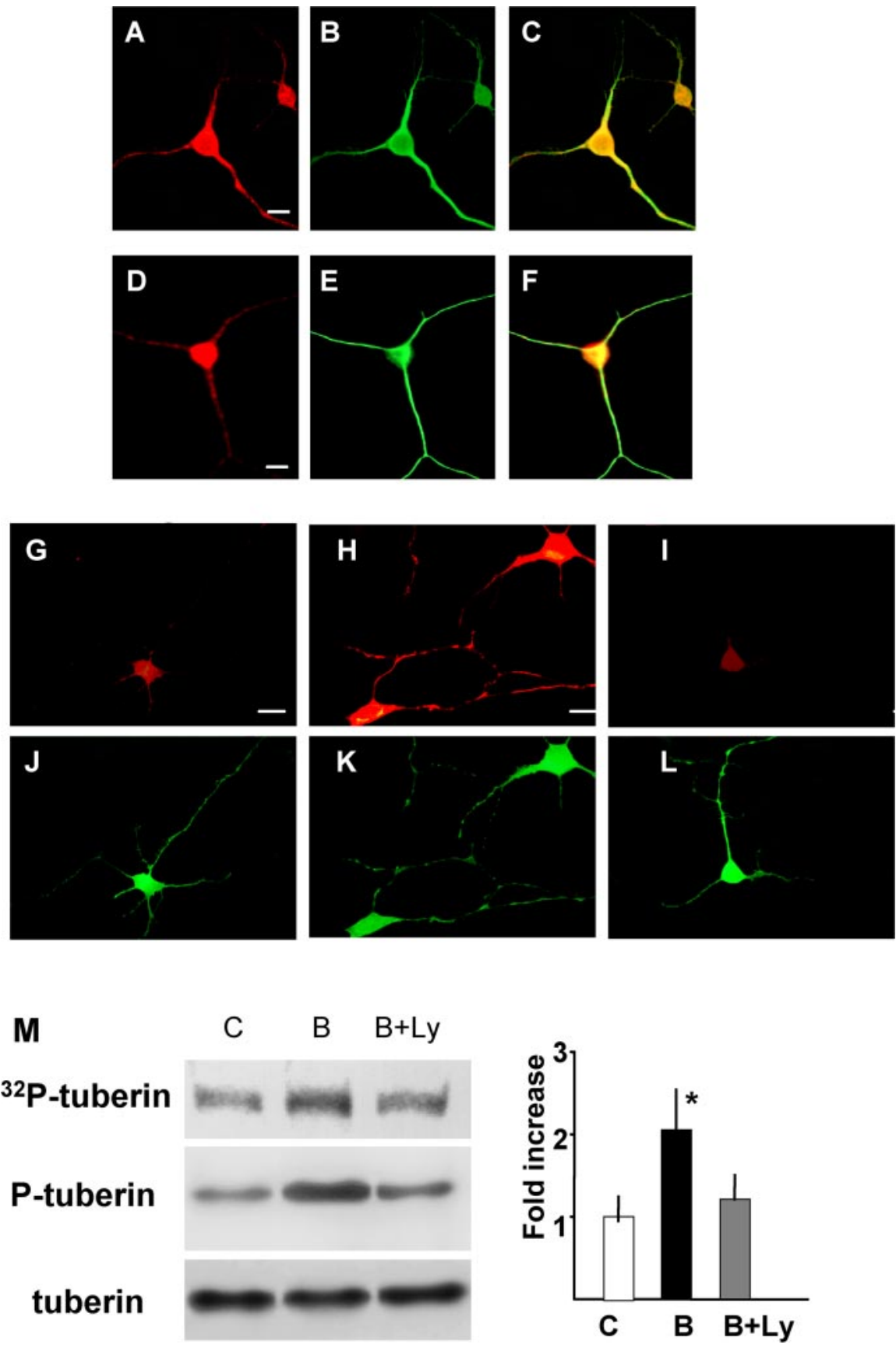

Figure 3. Distribution of tuberin and activation of tuberin by BDNF in dendrites. Double immunocytochemistry of tuberin $(A)$, RheB $(D)$, and MAP2 $(B, E)$. The merged image is shown in $C$ and $F$, respectively. Scale bars, $10 \mu \mathrm{m}$. Phosphorylation of tuberin in control $(G, J)$, BDNF (100 ng/ml)-treated $(H, K)$, and BDNF plus Ly294002 (10 $\mu \mathrm{M})$-treated $(I, L)$ neurons was detected by immunocytochemistry with anti-phospho-tuberin ( $G-l)$. Double immunostaining was performed with anti-MAP2 antibody ( $J$ L). Scale bars, $10 \mu \mathrm{m}$. M, Enhancement of tuberin phosphorylation was induced by BDNF in synaptoneurosomes. Synaptoneurosomes were incubated with or without BDNF and [ $\left.{ }^{32} \mathrm{P}\right] \gamma$-ATP. Samples were immunoprecipitated with anti-tuberin, and phosphorylated tuberin was detected by autoradiography after SDS-PAGE (top). Synaptoneurosome samples were also applied for Western blotting (middle and bottom). The right panel shows the result of densitometric analysis. Bars [white, control (C); black, BDNF (B); gray, BDNF plus Ly294002 (B+Ly)] represent means \pm SD $(n=4) .{ }^{*} p<0.005$ (ANOVA).

mTOR lead to a downregulation of translational activation induced by BDNF. Indeed, BDNF-induced enhancement of protein synthesis was blocked by mTOR siRNA transfection (Fig. $7 B)$. Levels of mTOR or downstream phosphorylation were unchanged between control RNA-treated and naive neurons under the absence or presence of BDNF. To examine the effect of mTOR siRNA transfection on dendritic translation, immunocytochem- 

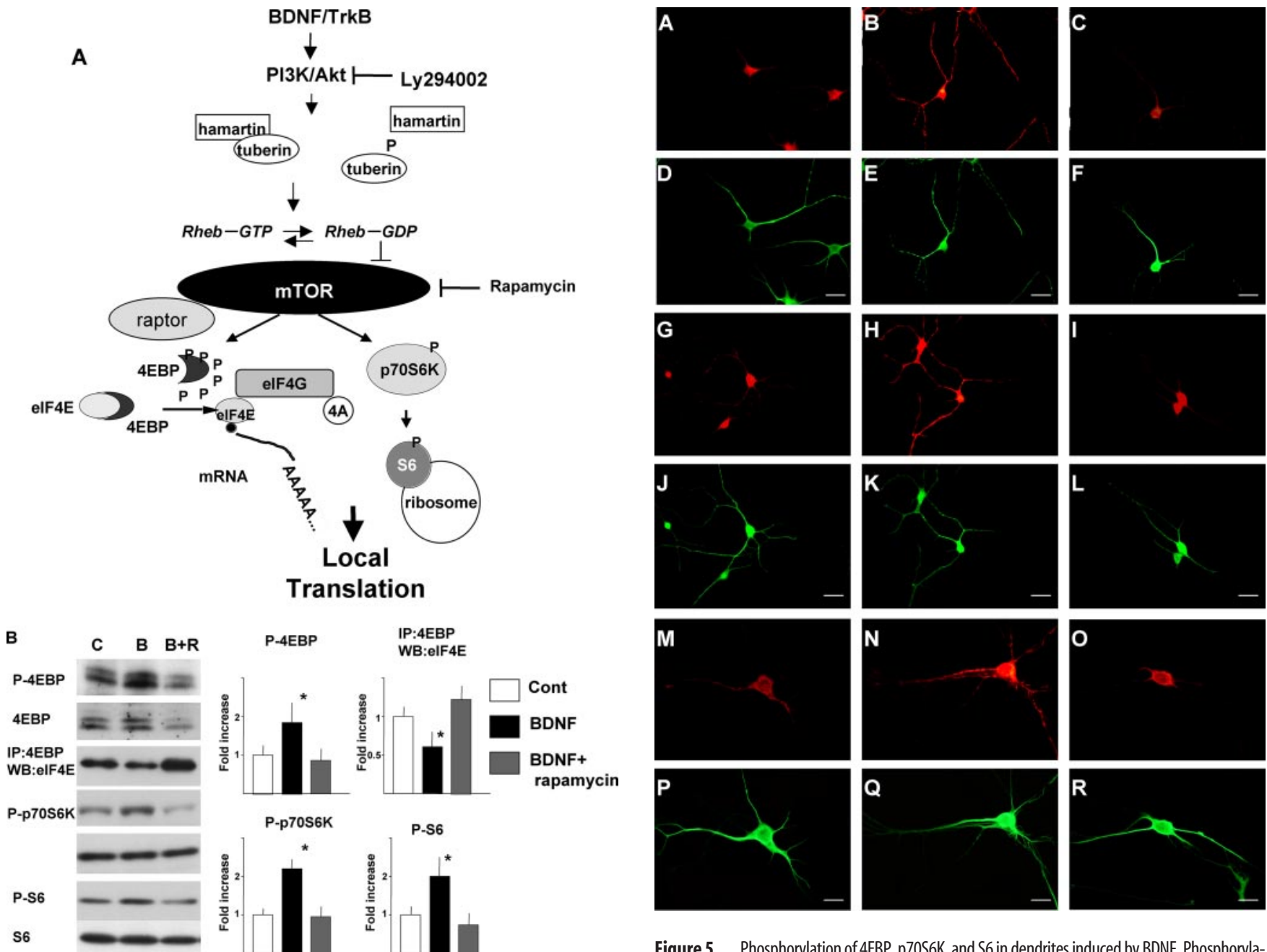

Figure 5. Phosphorylation of 4EBP, p70S6K, and $S 6$ in dendrites induced by BDNF. Phosphorylation of 4EBP ( $A-C)$, p70S6K ( $G-l)$, and S6 ( $P-R)$ in control $(A, G, M), \operatorname{BDNF}(100 \mathrm{ng} / \mathrm{ml})$-treated $(B, H$, $N)$, and BDNF plus rapamycin-treated $(C, I, 0)$ neurons was detected by immunocytochemistry with anti-phospho-specific antibodies (red fluorescence). Double immunostaining was performed with anti-MAP2 antibody (green fluorescence). Scale bars, $20 \mu \mathrm{m}$. $B, B D N F(100 \mathrm{ng} / \mathrm{ml}) ; B+R, B D N F$ plus rapamycin $(20 \mathrm{ng} / \mathrm{ml})$. The right panels show the results of densitometric analysis. Bars [white, control (Cont); black, BDNF; gray, BDNF plus rapamycin] represent means \pm SD $(n=4) .{ }^{*} p<0.005$ (ANOVA).

istry was performed. First, uptake of siRNA into neurons was monitored under a fluorescent microscope. Neurons were treated with mTOR siRNA labeled with FITC for $8 \mathrm{hr}$, fixed, and MAP2 immunocytochemistry was performed. Figure $8, A$ and $B$, shows low-magnification photomicrographs. Nearly all MAP2positive cells were also FITC positive, indicating that siRNA was introduced into most neurons. Under higher magnification, siRNA was seen not only in the cell bodies but also in dendrites (Fig. 8C,D). Triple immunocytochemistry was performed to examine the effect of mTOR siRNA on p70S6k phosphorylation in response to BDNF. After $48 \mathrm{hr}$ of mTOR siRNA or control RNA transfection, BDNF was applied to the culture. Neurons were fixed and immunostained with anti-MAP2 (Fig. $8 E, H$ ), antimTOR (Fig. 8F,I), and anti-phospho-p70S6K (Fig. 8G,J). mTOR siRNA transfection reduced mTOR (Fig. 8I) and phospho-p70S6K (Fig. 8J) in dendrites as well as in cell bodies. Control-treated neurons responded no differently to BDNF than naive neurons. As seen in Figure 8, $K$ and $L$, after treatment with siRNA targeting mTOR, levels of phospho-p70S6K were significantly reduced and were comparable with levels seen in BDNF plus rapamycin-treated cells.
Confirmation of dendritic activation of translation by BDNF To further ensure that the presence of phosphorylated molecules reflected local activation rather than their transport, we examined phosph-4EBP levels in isolated dendrites. In this preparation, dendrites were physically separated from cell bodies. Even in isolated dendrites, BDNF increased and rapamycin decreased the levels of phosphorylated 4EBP (Fig. $9 A-F$ ), indicating the local activation of mTOR-dependent translation in dendrites.

To examine local translation using an alternative strategy, BDNF was locally applied to the distal portion of a dendrite. Puff application of BDNF led to increased levels of phospho-S6 in a restricted area of the distal dendrite (Fig. 10). S6 is the downstream end point of mTOR signaling, and it is directly related to translation initiation. Therefore, these findings strongly suggest that BDNF induces local activation of translation at the site of stimulation.

\section{Discussion}

We have demonstrated rapamycin-sensitive, regulated local protein synthesis and mTOR (also known as FKBP12-rapamycinassociated protein, rapamycin and FKBP12 target 1, and RAPT)mediated local activation of the translation machinery by BDNF in neuronal dendrites. BDNF activated mTOR and its down- 
A

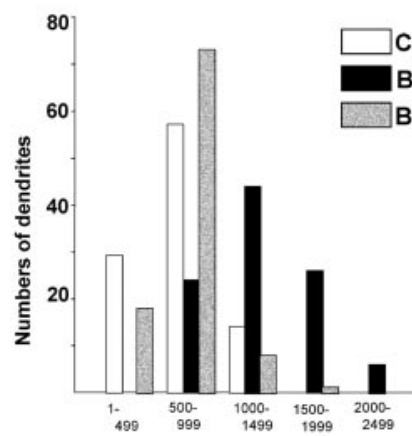

Fluorescence intensity/dendritc area $\left(u \mathrm{~m}^{2}\right)$
B

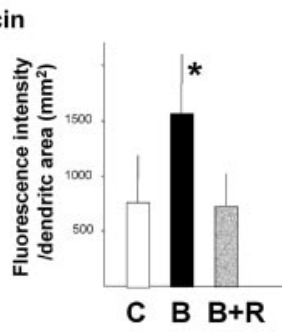

A

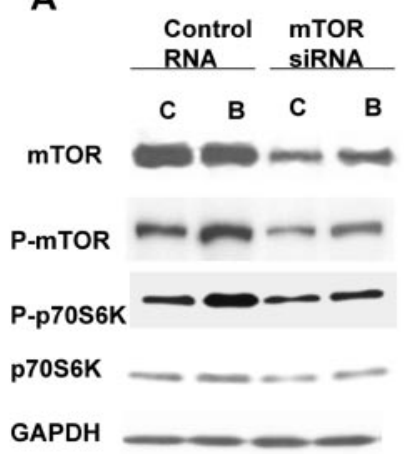

B

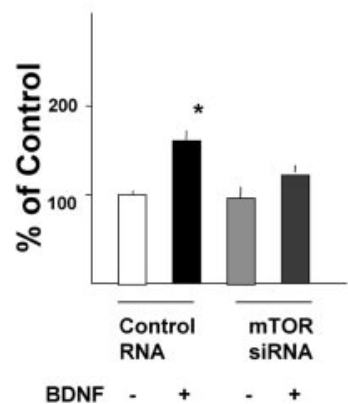

C

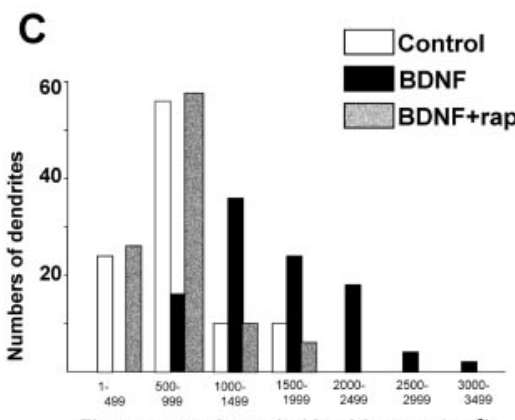

Fluorescence intensity/dendritc area $\left(\mu \mathrm{m}^{2}\right)$

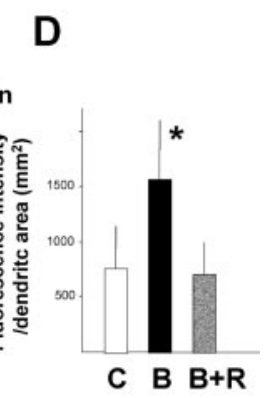

Figure 6. Quantitation of dendritic phosphorylation of 4EBP and p7056K. A summary histogram indicating the fluorescence intensity distributions for control ( $C$; white bars), BDNFtreated ( $B$; black bars), and BDNF plus rapamycin-treated ( $B+R$; gray bars) dendrites $(n=100$ of randomly chosen cells from 3-4 different culture dishes) is shown. The dendritic area was calculated by measuring MAP2-positive dendrites (green fluorescence), and the intensity of red fluorescence, which reflected phospho-4EBP $(A)$ or phospho-p7056K ( $C$ ) signal, in each dendrite was measured $(n=100)$. Summary diagrams indicating the mean intensity in dendrites of each condition are shown in $B$ (P-4EBP) and D (P-p70S6K). Bars represent mean + SD. ${ }^{*} p<$ 0.005 (ANOVA).

stream translation regulatory molecules such as 4EBP, p70S6K, and S6 (Fig. 4) in dendrites.

Multiple lines of evidence have emerged suggesting that local protein synthesis occurs in dendrites and plays an important role in synaptic plasticity under physiological conditions (Martin et al., 2000; Steward and Schuman, 2001; Jiang and Schuman, 2002). Local protein synthesis has been suggested by the presence of ribosomes and mRNAs in dendrites. Discovery of polysomes at dendritic shafts near the spines accelerated the study of local protein synthesis (Steward and Levy, 1982). In addition, several mRNAs such as CaMKII $\alpha$ (Benson et al., 1992), Arc (Lyford et al., 1995), MAP2 (Miyashiro et al., 1994), TrkB (Tongiorgi et al., 1997), and fragileX mental retardation protein (FMRP) (Weiler et al., 1997) were shown to localize at dendrites (Kiebler and DesGroseillers, 2000; Job and Eberwine, 2001). In addition to protein synthesis under basal states, certain extracellular stimuli enhanced local protein synthesis. Metabotropic glutamate receptor agonists stimulated the synthesis of FMRP (Weiler et al., 1997), and BDNF increased Arc translation (Yin et al., 2002) in synaptoneurosomes. Local protein synthesis in dendrites has been measured not only with classical methods using a radioisotope but also with real-time monitoring by optical imaging (Aakalu et al., 2001). We therefore wanted to examine the rapamycin sensitivity of Arc and CaMKII $\alpha$ synthesis in synaptoneurosomes in the presence or absence of BDNF. Interestingly, dif-
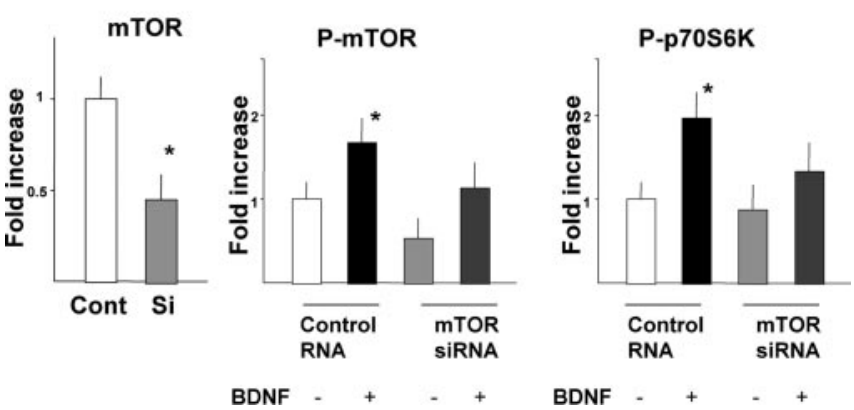

Figure 7. Effects of mTOR siRNA on mTOR protein levels and the phosphorylation state of p70S6K. Western blotting of mTOR and p70S6K, together with glyceraldehyde-3-phosphate dehydrogenase (GAPDH), under the presence or absence of mTOR siRNA with or without BDNF is shown. Phosphorylation of mTOR and p70S6K was also examined. Neurons incubated with control or mTOR siRNA for $48 \mathrm{hr}$ were treated with or without BDNF for $5 \mathrm{~min}(A)$. BDNF-induced protein synthesis is inhibited by mTOR siRNA $(B)$. Results of densitometric analysis are shown in C. Cont, Control; Si, siRNA. Bars represent mean + SD. ${ }^{*} p<0.005$ ( $t$ test) (mTOR, $n=8$; P-mTOR and P-p70S6K, $n=4)$. GAPDH and p70S6K levels are not changed by mTOR siRNA.

ferent proteins seem to be more responsive to local translation, and we could not detect the synthesis of MAP2 or TrkB. Enhanced Arc synthesis after BDNF treatment was completely inhibited by rapamycin, suggesting that this event was under the control of mTOR. In contrast, BDNF-induced CaMKII $\alpha$ synthesis was partially suppressed by rapamycin, suggesting the involvement of pathways other than the mTOR cascade. Recent findings have identified a novel mechanism regulating CaMKII $\alpha$ translation. Cytoplasmic polyadenylation element-binding protein (CPEB) mediates CaMKIIa translation through its unique interactions with translation factors. CPEB controls the translation of certain sets of mRNAs (Wu et al., 1998; Mendez and Richter, 2001) and is activated by NMDA through aurora kinase (Huang et al., 2002). BDNF might be an alternative stimulator of CPEB and thereby enhance CaMKII $\alpha$ mRNA translation in dendrites. In this study, we found that BDNF not only increased levels of individual proteins such as Arc or CaMKII but also elevated total protein synthesis in dendrites, as well as in whole neurons (Takei et al., 2001). The increase in total protein synthesis mediated by BDNF was mostly suppressed by rapamycin. Rapamycin is a macrolide immunosuppressant that inhibits the activity of mTOR. Thus, the majority of dendritic protein synthesis induced by BDNF is likely controlled by the mTOR signaling pathway.

Although the concept of local protein synthesis is becoming clearer, the mechanism by which extracellular stimulation enhances local protein synthesis is not yet known. Translation factors tightly control protein synthesis in a dynamic manner in 

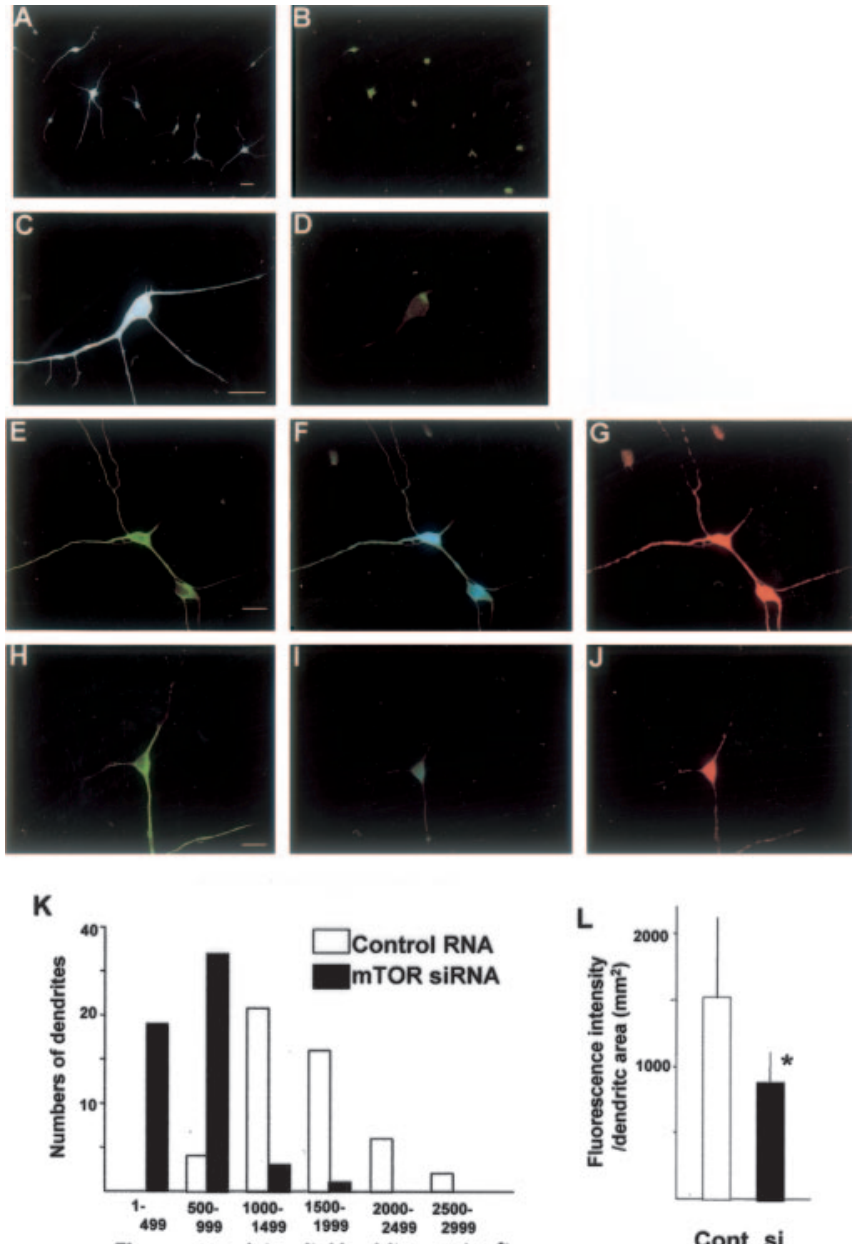

Fluorescence intensity/dendritc area $\left(\mu \mathrm{m}^{2}\right)$
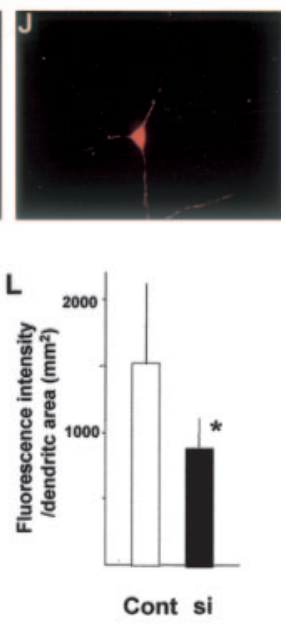

Figure 8. Uptake of mTOR siRNA into neurons and the effects of mTOR siRNA on mTOR protein level and downstream P-p7056K. Neurons were incubated with mTOR siRNA labeled with FITC for $8 \mathrm{hr}$ and immunostained with mouse monoclonal anti-MAP2 antibody. MAP2 signal was visualized with pacific blue-labeled anti-mouse $\lg G(A, C)$. siRNA taken up into neurons was detected as green (FITC) fluorescence $(B, D)$. $C$ and $D$ are higher-magnification photomicrographs. Triple immunocytochemistry with anti-MAP2 (chick), anti-mTOR (rabbit), and anti-phospho-p70S6K (mouse) and visualized with FITC-conjugated anti-chick lgG (green), pacific blue-conjugated anti-rabbit lgG (blue), and Alexa546-conjugated anti-mouse lgG (red), respectively, is shown. Neurons incubated with control $(E-G)$ or mTOR $(H-J)$ siRNA for $48 \mathrm{hr}$ were treated with BDNF. Scale bars, $10 \mu \mathrm{m}$. A summary histogram indicating the fluorescence intensity distributions for control or mTOR siRNA-treated dendrites $(n=100)$ is shown. The dendritic area is calculated by measuring MAP2-positive dendrites (green fluorescence), and the intensity of red fluorescence, which reflects phospho-S6K signal, in each dendrite is measured $(K)$. A summary diagram indicating the mean intensity in dendrites of both conditions is shown in L. Cont, Control; si, siRNA. Bars represent mean + SD. ${ }^{*} p<0.005$ ( $t$ test).

response to cellular stimuli (Mathews et al., 2000). To better understand the events surrounding translation initiation in dendrites, we first examined the distribution of mTOR and raptor, a recently identified mTOR-binding partner (Hara et al., 2002; Kim et al., 2002) that functions as a scaffold protein for the mTOR-catalyzed phosphorylation of 4EBP and p70S6K (Isotani et al., 1999). Both mTOR and raptor colocalized with MAP2 in the dendrites of cortical neurons. Interestingly, mTORassociated raptor was enriched in synaptoneurosomes relative to denucleated total lysate; such an association could lead to more rapid activation of mTOR signaling in dendrites in response to extracellular stimuli. Treatment of dendrites with BDNF led to increased phosphorylation of mTOR, and these molecules were enzymatically active as assessed by in vitro kinase assays.
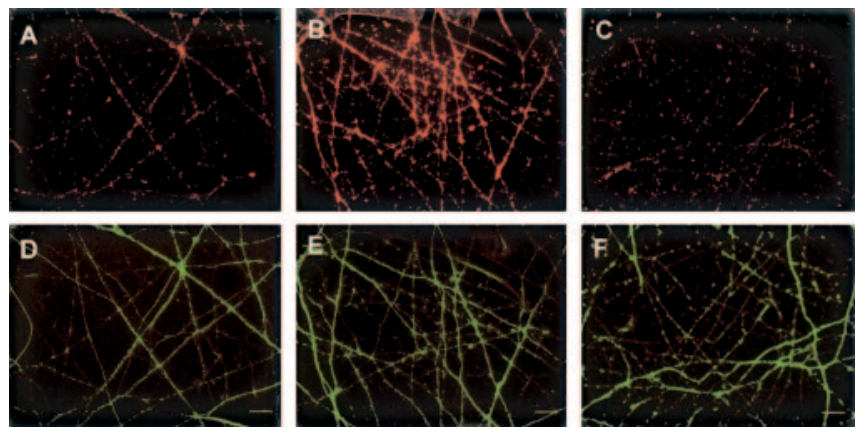

Figure 9. Phosphorylation of $4 E B P$ in isolated dendrites induced by BDNF. Double immunocytochemistry of phospho-4EBP $(A-C)$ and MAP2 $(D-F)$ in isolated dendrites is shown for control $(A, D)$, $\operatorname{BDNF}(100 \mathrm{ng} / \mathrm{ml})(B, E)$, and BDNF plus rapamycin $(20 \mathrm{ng} / \mathrm{ml})(C, F)$. Scale bars, $10 \mu \mathrm{m}$.

mTOR activity is thought to be primarily controlled by nutrients such as branched chain amino acids in many cell types (Proud, 2002). In neurons, we previously showed that BDNF strongly activated mTOR (Takei et al., 2001). Thus, to elucidate the pathway leading from BDNF/TrkB to mTOR activation, the distribution and activation of tuberin were examined. Tuberin, a tumor suppressor gene (TSC2) product, is thought to be an upstream suppressor of mTOR together with hamartin (Tee et al., 2002). Once phosphorylated, tuberin dissociates from hamartin, and the suppression of mTOR is removed (Kwiatkowski, 2003). Recently, tuberin was identified as a GTPase-activating protein for Rheb, a Ras family small G-protein (Inoki et al., 2003; Tee et al., 2003; Zhang et al., 2003). Indeed, Rheb is found in dendrites, and it is activated after BDNF treatment of total cultured neurons (our unpublished data). Rheb may be converted to its active, GTP-bound form after tuberin phosphorylation and lead to mTOR activation in dendrites. Tuberin is present in neuronal dendrites, and it becomes phosphorylated in dendrites and synaptoneurosome in response to BDNF stimulation. Thus, BDNF may activate mTOR through tuberin phosphorylation and Rheb activation in dendrites. mTOR phosphorylates two different downstream factors, 4EBP and S6K, both of which are involved in translation initiation. Thus, activation of mTOR enhances both cap-dependent translation (eIF4F pathway) and initiaition of 5' oligopyrimidine tract-containing mRNAs (S6K-S6 pathway). The majority of these mRNAs is growth-associated proteins such as ribosomal proteins and elongation factors. Thus, mTOR mediates multiple pathways of translational control in neurons.

BDNF treatment leads to increased phosphorylation of the mTOR targets 4EBP (Thr37) and p70S6k (The389) in dendrites and synaptoneurosomes. Phosphorylation of S6, a substrate of p70S6K, was also detected in dendrites. Although cells were extracted in the presence of anti-BDNF antibody, the relatively high levels of residual phosphorylation in control synaptoneurosomes are possibly attributable to leakage of endogenous BDNF from cells. Rapamycin alone might inhibit this activation.

Although it is thought that rapamycin is a highly specific inhibitor of mTOR, the possibility that rapamycin affects other unknown kinases or molecules cannot be completely excluded. To confirm these findings, an mTOR knock-out or dominant negative is needed; these have yet to be described, however. Thus, we used RNA interference to knock down mTOR levels in neurons. siRNA successfully and specifically reduced mTOR in neurons. In the dendrites of siRNA-treated neurons, the translational activation induced by BDNF was reduced. These results further confirm the essential role of mTOR in BDNF-induced local translational activation and local protein synthesis enhancement. 

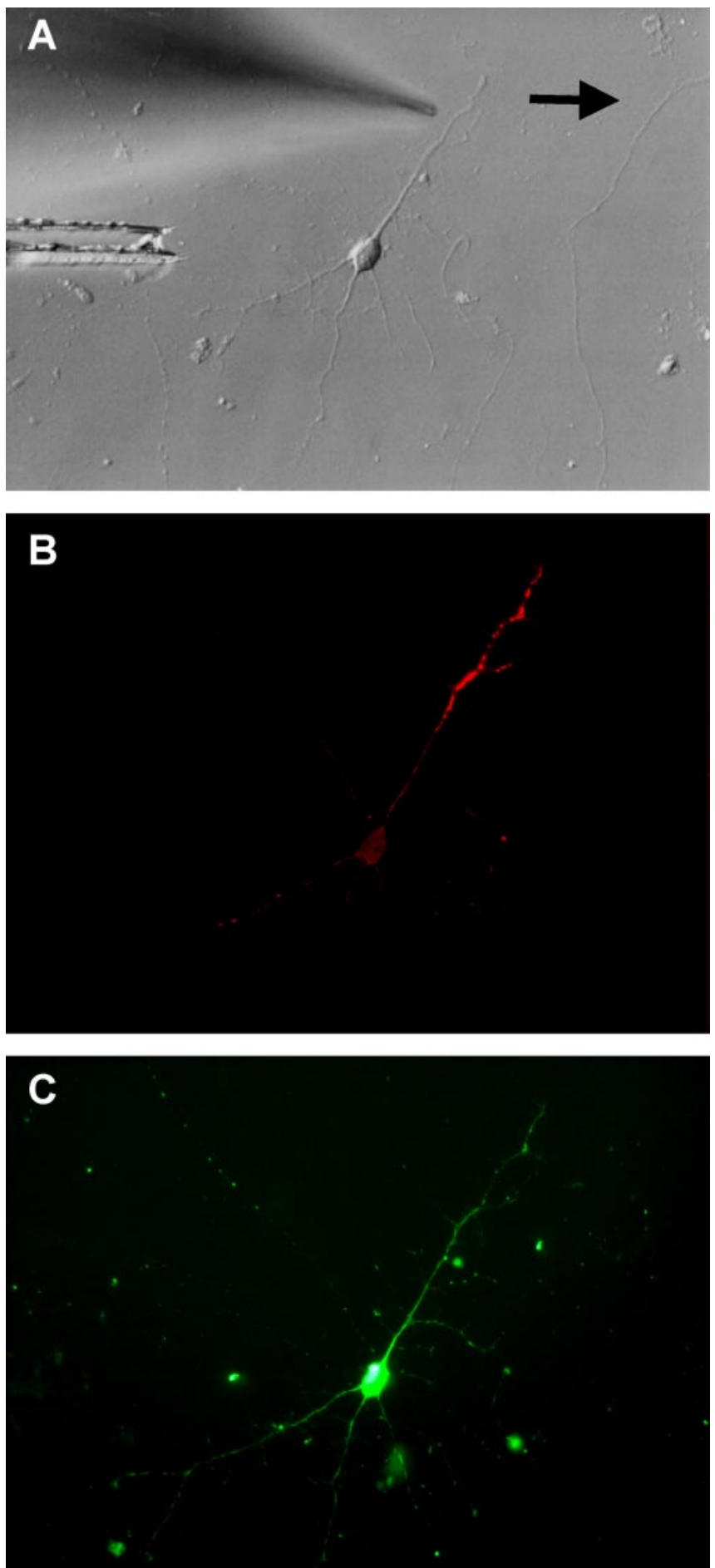

Figure 10. Local phosphorylation of $\$ 6$ by puff application of BDNF. Double immunocytochemistry of phospho-S6 ( $B$ ) and MAP2 ( $C$ is shown. A phase-contrast photomicrograph of the same neuron is shown in $A$. The arrow indicates the direction of flow. Scale bar, $10 \mathrm{~mm}$.

Although increased phosphorylation of all molecules examined was observed within $5 \mathrm{~min}$, the possibility that phosphorylated molecules were transported from the cell bodies to dendrites could not be excluded. Similarly, the synaptoneurosome fraction may contain some elements from soma or glia. To rule out these possibilities, we prepared isolated dendrites by the method of Torre and Steward (1992). In these samples, the major population of neurites was MAP2 positive. There was little con- tamination of cell bodies of neurons and only occasional contamination with glial cells. When properly prepared, samples were negative for nuclear staining as assessed by propidium iodide. Only samples that met these criteria were used for additional assays; the results therefore reflect reactions occurring mainly in dendrites and occasionally in axons. In these preparations, BDNF increased the amount of phospho-4EBP in a rapamycin-sensitive manner. Using this method, we demonstrated mTOR-dependent protein synthesis and translational activation in dendrites. Additional evidence for local translational activation was obtained from the puff application of BDNF. The application of BDNF to a restricted area of a dendrite induced the focal phosphorylation of S6, an end point of mTOR signaling in distal dendrites. Although the use of immunoelectron microscopy is needed to clarify the precise location of this signaling, this translational activation might reflect certain clusters of synapse reaction, when considering the postsynaptic, local action of BDNF (Kohara et al., 2001; Nawa and Takei, 2001). The present data strongly suggest that BDNF locally induces translational signaling from the beginning (TrkB activation) to the end (S6 phosphorylation) in dendrites.

Regulation of protein synthesis is thought to be required for synaptic plasticity because recent studies have shown that rapamycin (Casadio et al., 1999; Tang et al., 2002), as well as translation inhibitors such as cyclohexamide or anisomycin, disrupts these processes (Kang and Schuman, 1996; Huber et al., 2000; Karachot et al., 2001). mTOR-mediated signals may play crucial roles in both local protein synthesis and synaptic plasticity. In addition, inhibition of cap binding by injecting neurons with the cap analog $\mathrm{m}^{7} \mathrm{GTP}$ suppressed long-term depression (Huber et al., 2000; Karachot et al., 2001). Recently, we reported that 4EBP phosphorylation in rat hippocampus was increased after spatial learning (Mizuno et al., 2003). This suggests that mTOR signaling is involved in higher brain function.

Here, we demonstrated the activation of mTOR and 4EBP phosphorylation, which are key steps for cap-dependent translation, induced by BDNF in neuronal dendrites. Thus, certain kinds of synaptic plasticity induced by BDNF might be mediated by mTOR-dependent, regulated local translation in neuronal dendrites.

\section{References}

Aakalu G, Smith WB, Nguyen N, Jiang C, Schuman EM (2001) Dynamic visualization of local protein synthesis in hippocampal neurons. Neuron 30:489-502.

Bailey CH, Barad M, Kandel ER (1996) Toward a molecular definition of long-term memory storage. Proc Natl Acad Sci USA 93:13445-13452.

Benson DI, Gall CM, Isackson PJ (1992) Dendritic localization of type II calcium calmodulin-dependent protein kinase mRNA in normal and reinnervated rat hippocampus. Neuroscience 46:851-857.

Casadio A, Martin KC, Giustetto M, Zhu H, Chen M, Bartsch D, Bailey CH, Kandel ER (1999) A transient, neuron-wide form of CREB-mediated long-term facilitation can be stabilized at specific synapses by local protein synthesis. Cell 99:221-237.

Fumagalli S, Thomas G (2000) S6 phosphorylation and signal transduction. In: Translational control in gene expression (Sonenberg N, Hershey JWB, Mathews MB, eds), pp 695-717. Cold Spring Harbor, NY: Cold Spring Harbor Laboratory.

Gao X, Zhang Y, Arrazola P, Hino O, Kobayashi T, Yeung RS, Ru B, Pan D (2002) Tsc tumor suppressor proteins antagonize amino-acid-TOR signaling. Nat Cell Biol 4:699-704.

Gardiol A, Racca C, Triller A (1999) Dendritic and postsynaptic protein synthetic machinery. J Neurosci 19:168-179.

Gingras AC, Raught B, Sonenberg N (2001) Regulation of translation initiation by FRAP/mTOR. Genes Dev 15:807-826.

Hara K, Maruki Y, Long X, Yoshino K, Oshiro N, Hidayat S, Tokunaga C, 
Avruch J, Yonezawa K (2002) Raptor, a binding partner of target of rapamycin (TOR), mediates TOR action. Cell 110:177-189.

Huang YS, Jung MY, Sarkissian M, Richter JD (2002) N-methyl-D-aspartate receptor signaling results in aurora kinase-catalyzed CPEB phosphorylation and alpha CaMKII mRNA polyadenylation at synapses. EMBO J 21:2139-2148.

Huber KM, Kayser MS, Bear MF (2000) Role for rapid dendritic protein synthesis in hippocampal mGluR-dependent long-term depression. Science 288:1254-1257.

Inamura N, Hoshino S, Uchiumi T, Nawa H, Takei N (2003) Cellular and subcellular distributions of translation initiation, elongation and release factors in rat hippocampus. Mol Brain Res 111:165-174.

Inoki K, Li Y, Zhu T, Wu J, Guan KL (2002) TSC2 is phosphorylated and inhibited by Akt and suppresses mTOR signaling. Nat Cell Biol 4:648-657.

Inoki K, Li Y, Xu T, Guan K-L (2003) Rheb GTPase is a direct target of TSC2 GAP activity and regulates mTOR signaling. Genes Dev 17:1829-1834.

Isotani S, Hara K, Tokunaga C, Inoue H, Avruch J, Yonezawa K (1999) Immunopurified mammalian target of rapamycin phosphorylates and activates p70 S6 kinase alpha in vitro. J Biol Chem 274:34493-34498.

Jiang C, Schuman EM (2002) Regulation and function of local protein synthesis in neuronal dendrites. Trends Biochem Sci 27:506-513.

Job C, Eberwine J (2001) Localization and translation of mRNA in dendrites and axons. Nat Rev Neurosci 2:889-898.

Kang H, Schuman EM (1996) A requirement for local protein synthesis in neurotrophin-induced hippocampal synaptic plasticity. Science 273:1402-1406.

Karachot L, Shirai Y, Vigot R, Yamamori T, Ito M (2001) Induction of longterm depression in cerebellar Purkinje cells requires a rapidly turned over protein. J Neurophysiol 86:280-289.

Kiebler MA, DesGroseillers L (2000) Molecular insights into mRNA transport and local translation in the mammalian nervous system. Neuron $25: 19-28$.

Kim DH, Sarbassov DD, Ali SM, King JE, Latek RR, Erdjument-Bromage H, Tempst P, Sabatini DM (2002) mTOR interacts with raptor to form a nutrient-sensitive complex that signals to the cell growth machinery. Cell 110:163-175.

Kohara K, Kitamura A, Morishima M, Tsumoto T (2001) Activitydependent transfer of brain-derived neurotrophic factor to postsynaptic neurons. Science 291:2419-2423.

Kristof AS, Marks-Konczalik J, Billings E, Moss J (2003) Stimulation of signal transducer and activator of transcription-1 (STAT1)-dependent gene transcription by lipopolysaccharide and interferon is regulated by mammalian target of rapamycin J Biol Chem 278:33637-33644.

Kwiatkowski DJ (2003) Tuberous sclerosis: from tubers to mTOR. Ann Hum Genet 67:87-96.

Lyford GL, Yamagata K, Kaufman WE, Barnes CA, Sanders LK, Copeland NG, Gilbert DJ, Jenkins NA, Lanahan AA, Worley PF (1995) Arc, a growth factor and activity-regulated gene, encodes a novel cytoskeletonassociated protein that is enriched in neuronal dendrites. Neuron 14:433-445.

Martin KC, Barad M, Kandel ER (2000) Local protein synthesis and its role in synapse-specific plasticity. Curr Opin Neurobiol 10:587-592.

Mathews MB, Sonenberg N, Hershey JWB (2000) Origins and principles of translational control. In: Translational control in gene expression (Sonenberg N, Hershey JWB, Mathews MB, eds), pp 1-32. Cold Spring Harbor, NY: Cold Spring Harbor Laboratory.

Mendez R, Richter JD (2001) Translational control by CPEB: a means to the end. Nat Rev Mol Cell Biol 2:521-529.

Miyashiro K, Dichter M, Eberwine J (1994) On the nature and differential distribution of mRNAs in hippocampal neurites: implication for neuronal functioning. Proc Natl Acad Sci USA 91:10800-10804.

Mizuno M, Yamada K, Takei N, Tran MH, He J, Nakajima A, Nawa H,
Nabeshima T (2003) Phosphatidylinositol 3-kinase: a molecule mediating BDNF-dependent spatial memory formation. Mol Psychiatry $8: 217-224$

Nawa H, Takei N (2001) BDNF as an anterophin; a novel neurotrophic relationship between brain neurons. Trends Neurosci 24:683-684.

Nishiuma T, Hara K, Tsujishita Y, Kaneko K, Shii K, Yonezawa K (1998) Characterization of the phosphoproteins and protein kinase activity in mTOR immunoprecipitates. Biochem Biophys Res Commun 252:440-444

Poo MM (2001) Neurotrophins as synaptic modulators. Nat Rev Neurosci $2: 24-32$.

Proud CG (2002) Regulation of mammalian translation factors by nutrients. Eur J Biochem 269:5338-5349.

Scheetz AJ, Nairn AC, Constantine-Paton M (2000) NMDA receptormediated control of protein synthesis at developing synapses. Nat Neurosci 3:211-216.

Steward O, Levy WB (1982) Preferential localization of polyribosomes under the base of dendritic spines in granule cells of the dentate gyrus. J Neurosci 2:284-291.

Steward O, Schuman EM (2001) Protein synthesis at synaptic sites on dendrites. Annu Rev Neurosci 24:299-325.

Takei N, Numakawa T, Kozaki S, Sakai N, Endo Y, Takahashi M, Hatanaka H (1998) Brain-derived neurotrophic factor directly induces rapid and transient release of glutamate from cortical neurons. J Biol Chem 273:27620-27624.

Takei N, Kawamura M, Hara K, Yonezawa K, Nawa H (2001) Brain-derived neurotrophic factor enhances neuronal translation by activating multiple initiation processes: comparison with the effects of insulin. J Biol Chem 276:42818-42825.

Tang SJ, Reis G, Kang H, Gingras AC, Sonenberg N, Schuman EM (2002) A rapamycin-sensitive signaling pathway contributes to long-term synaptic plasticity in the hippocampus. Proc Natl Acad Sci USA 99:467-472.

Tee AR, Fingar DC, Manning BD, Kwiatkowski DJ, Cantley LC, Blenis J (2002) Tuberous sclerposis complex-1 and -2 gene products function together to inhibit mammalian target of rapamycin (mTOR)-mediated downstream signaling. Proc Natl Acad Sci USA 99:13571-13576.

Tee AR, Manning BD, Roux PP, Cantley LC, Blenis J (2003) Tuberous sclerosis complex gene product, tuberin and hamartin, control mTOR signaling by acting as a GTPase-activating protein complex toward Rheb. Curr Biol 13:1259-1268.

Thoenen H (1995) Neurotrophins and neuronal plasticity. Science 270:593-598.

Tongiorgi E, Righi M, Cattaneo A (1997) Activity-dependent dendritic targeting of BDNF and TrkB mRNAs in hippocampal neurons. J Neurosci 17:9492-9505.

Torre E, Steward O (1992) Demonstration of local protein synthesis within dendrites using a new culture system that permits the isolation of living axons and dendrites from their cell bodies. J Neurosci 12:762-772.

Weiler IJ, Irwin SA, Klinstova AV, Spencer CM, Brazelton AD, Miyashiro K, Comery TA, Patel B, Eberwine J, Greenough WT (1997) Fragile X mental retardation protein is translated near synapses in response to neurotransmitter activation. Proc Natl Acad Sci USA 94:5395-5400.

Wu L, Wells D, Tay J, Mendis D, Abbott MA, Barnitt A, Quinlan E, Heynen A, Fallon JR, Richter JD (1998) CPEB-mediated cytoplasmic polyadenylation and the regulation of experience-dependent translation of alphaCaMKII mRNA at synapses. Neuron 21:1129-1139.

Yin Y, Edelman GM, Vanderklish PW (2002) The brain-derived neurotrophic factor enhances synthesis of Arc in synaptoneurosomes. Proc Natl Acad Sci USA 99:2368-2373.

Zhang Y, Gao X, Saucedo LJ, Ru B, Edgar BA, Pan D (2003) Rheb is a direct target of the tuberous sclelosis tumor suppressor proteins. Nat Cell Biol 5:578-581. 